\title{
TAKE CARE WHEN NAMING FUNGI
}

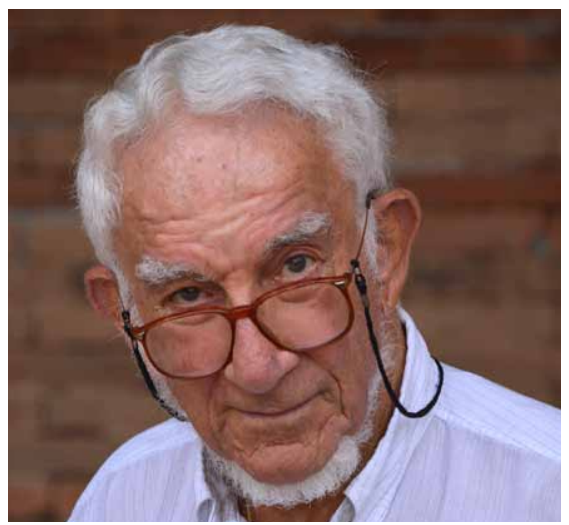

Courtesy Robert Lücking.

$\mathrm{T}$ he names of living organisms used to convey associations about properties, origin, substrate, host, history, etc. of the organism, a help to memorize the name. Names of fungi obey the International Codes, formerly of Botanical Nomenclature, now of Nomenclature for algae, fungi, and plants (ICN), and are supposed to be formed in accordance with certain rules. Principle V of this Code explicitly states: "Scientific names of taxonomic groups are treated as Latin regardless of their derivation." Articles 60-62 present detailed rules about grammar and orthography, according to which the names are to be formed. Most important is that an adjectival epithet must agree in gender with that of the generic name. Names (especially those of species epithets) formed contrary to the rules are to be corrected according to Art. 32.2: "Names or epithets published with an improper Latin termination but otherwise in accordance with this Code are regarded as validly published; they are to be changed to accord with Art. 16-19, 21, 23, and 24, without change of the author citation or date (see also Art. 60.12)".

With the new ICN (McNeill et al. 2012) the former requirement of Latin diagnoses (as an independent lingua franca) for newly introduced taxa has been abandoned because too few linguistically trained biologists can nowadays comply with this rule, and the "Latin" diagnoses published in recent years were generally of very poor quality, hardly understandable to anyone without recourse to the diagnosis in the original language. This does not mean that some linguistic knowledge is still needed in disclosing the old literature and in coining appropriate names.

This editorial is motivated by the publication of new generic names, in which my authorship is appended, in Lombard et al. (2015), but where sadly I did not have the chance of checking the final text before publication. Thus there is now a genus Bisifusarium, which is supposed to reflect "the two-celled macroconidia characteristically formed by these fungi", and not a product of Italian cuisine. It would have been easy enough to express this information correctly in names like Dimerofusarium, Didymofusarium, or others. Other incorrectly formed names published in this paper and elsewhere hopefully will be corrected through MycoBank.

To be an author of a fungal name means responsibility. I have quite often declined co-authorship with a name when I had not at least seen the fungus in question. This attitude is at variance with the habit of some leading mycologists to stamp their name on all and everything in their surroundings. Thus their name no longer serves as a seal of quality for the underlying research.

A great need for new names stems from the molecular discovery of large numbers of novelties, whose baptizing often goes over the mycologists' head who then seek refuge in awkward derivatives of previously formed names with prefixes such as Pseudo-, Para-, Xeno-, or suffixes like-oides, -opsis, or -ella. This practice is unpleasant and families of similar names become a source of confusion. It is especially curious when another author is "honoured" by a combination of his/ her name with the ending -opsis in a genus, which suggests a similarity of the genus with that mycologist. Can mycologists not adopt the habit of consulting classically trained colleagues in order to coin somewhat more informative names?

Lombard L, van der Merwe NA, Groenewald JZ, Crous PW (2015) Generic concepts in

Nectriaceae. Studies in. Mycology 80: 189-245. McNeill J, Barrie FR, Buck WR, Demoulin V,

Greuter W, et al. (2012) International Code of Nomenclature for algae, fungi, and plants (Melbourne Code), adopted by the Eighteenth International Botanical Congress Melbourne, Australia, July 2011. [Regnum Vegetabile no. 154.] Königstein: Koeltz Scientific Books.

Walter Gams

(email:walter.gams@online.nl)

\section{Guidance on coining scientific names}

Remember scientific names are Latinized and not Latin, and that they can be derived from any source, and may even be anagrams (e.g. Milospium based on Spilomium) or based on acronyms (e.g. Isia based on International Scientific Instruments). It is not forbidden to latinize jokes, as in Woswasia (Austrian dialect: "Wos waass i" = what do I know), while direct "latinization" of words in other languages, such as cannonballus is less elegant. Most mycologists will be familiar with Botanical Latin (Stearn 1992), but perhaps not with Cash (1965) or Short \& George (2013).

Latinized scientific names are not just the province of botanists and mycologists, and when it comes to finding appropriately descriptive words there are several compilations that may give inspiration: Brown (1956), Jaeger (1955), and Nybakken (1959), all of which have been reprinted several times.

Although it is not a requirement at present, always try to avoid introducing a new generic name that is identical with one that is in use in zoology or another kingdom; a check on names accepted in the Species 2000 Catalogue of Life, which is updated annually (http://www. species2000.org/), only takes a few minutes. Perpetuating duplication is particularly confusing when retrieving data in the electronic age.

And if you wish to be amused by weird and inappropriate examples, there are many in the recent book by Wright (2014), an amateur mycologist and mycophagist. 
Brown RW (1956) Composition of Scientific Words. Revd edn. Washington DC: Smithsonian Institution Press. Cash EK (1965) A Mycological English-Latin Glossary. [Mycologia Memoir no. 1.] New York: Hafner Publishing. Jaeger EC (1955) A Source-book of Biological Names and Terms. Springfield, IL: C C Thomas.

Nybakken OE (1959) Greek and Latin in Scientific Terminology. Ames, IA: Iowa State University Press.

Short E, George A (2013) A Primer of Botanical Latin with Vocabulary. Cambridge: Cambridge University Press. Stearn WT (1992) Botanical Latin. $4^{\text {th }}$ edn. Newton Abbot: David \& Charles.

Wright J (2014) The Naming of the Shrew: a curious history of Latin names. London: Bloomsbury. 